\title{
From Research to Practical Application: Knowledge Transfer Planning and Execution in Outsourcing
}

\author{
Sabine Madsen ${ }^{1}$, Keld Bødker ${ }^{1}$, and Thomas Tøth ${ }^{2}$ \\ ${ }^{1}$ Roskilde University, Department of Communication, \\ Business and Information Technologies, Universitetsvej 1, DK-4000 Roskilde, Denmark \\ \{sabinem, keldb\}@ruc. dk \\ ${ }^{2}$ Copenhagen Business School, Department of Intercultural Communication and Management, \\ Porcelænshaven 18A. DK-2000, Frederiksberg C, Denmark \\ tto.ikl@cbs.dk
}

\begin{abstract}
Despite an abundance of literature about knowledge and outsourcing the theoretical concepts and research findings are not immediately applicable in practice. In this paper we present the insights and the effort used to find a way to support knowledge transfer in outsourcing. More specifically, we aim to support operational managers responsible for outsourced IT activities in carrying out the concrete task of knowledge transfer planning and execution. We report from a longitudinal project conducted in a major financial company headquartered in Denmark and an offshore development center located in India. We identify the three main knowledge transfer challenges experienced by the case company. The identified challenges inform the design of a systematic five-step approach to the company's knowledge transfer. Our main contribution is to illustrate how extant research can be applied to understand and solve a particular company's knowledge transfer challenges in a way that fits with the company culture.
\end{abstract}

Keywords: outsourcing, offshoring, knowledge transfer, IT development and maintenance, engaged scholarship.

\section{Introduction}

Research shows and companies know that it takes time before employees who are newcomers to an organization, or to a specific department, job, or project achieve the same level of productivity as their colleagues (Rollag et al., 2005). Similarly, it is recognized that to get newcomers up to speed, they have to be introduced to and learn about their tasks and the particular context in which they are to perform these tasks (ibid.). Many companies handle this challenge through formal introduction programs, and subsequent on-the-job training, where experienced colleagues show the newcomers the robes. Moreover, much knowledge transfer takes place informally and ad hoc through co-presence and socialization (Nonaka, 1991; 1994; Nonaka and Takeuchi, 1995). However, when it comes to outsourcing of activities to another company, the lack of co-location and opportunities for spontaneous interaction mean 
that knowledge transfer between employees from the two companies does not happen as easily, if at all (Carmel and Agarwal, 2001; Kotlarsky and Oshri, 2005; Oshri et al., 2008). In case of outsourcing to offshore destinations this is further complicated (ibid.). In this paper, we discuss knowledge transfer in such a situation based on a longitudinal case study.

The project took place in Danske Bank - a major financial company operating in northern Europe. Danske Bank has operational experience with a dedicated offshore development center (ODC) in India since 2005. Five hundred Indian associates work in different IT development projects and in various system management areas in close cooperation with employees from the company situated in Denmark. To enable this, initial training programs have been set up. Following the initial training program, the Danish managers who are responsible for outsourced IT activities have to ensure that further knowledge transfer about the domain and/or the activities takes place. This means that they have to figure out what kind of knowledge the Indian associates need and how to transfer it. Geographical distance and cultural differences add to the complexity of this task. In addition, for most of these managers an explicit focus on knowledge transfer is still a new and somewhat unknown area, for which they have had no formal training.

In this paper, we address the research question: How can a systematic approach help managers establish and execute a knowledge transfer plan that overcomes the challenges of knowledge transfer in offshore outsourcing of IT related activities? Further we wish to illustrate the efforts it takes to move insights from research into practice. As such, the target audience of this paper is researchers and middle/operational managers who are interested in understanding and solving knowledge transfer challenges in outsourcing in practice - by drawing on and grounding their work in the already existing literature and theoretical concepts about knowledge and outsourcing.

The paper is structured as follows. In Section 2 we review relevant literature and identify the theoretical concepts and understandings that have shaped our research, and in section 3 we describe our research approach. Section 4 presents the case company, its outsourcing arrangement, and experienced knowledge transfer challenges. Based on an understanding of these challenges, in Section 5, we propose a systematic five-step approach to the case company's knowledge transfer. In section 6 we discuss the advantages and disadvantages of the suggested approach. The discussion is structured around a framework that emphasizes the instrumental, aesthetic and symbolic dimensions of artifacts (Vilnai-Yavetz and Rafaeli, 2006). Lastly, in the conclusion we present a short summary of our research.

\section{Background}

Knowledge is a multifaceted phenomenon that has been researched at the individual and at organizational level, and as something that is inherent to action, necessary for interaction, and embedded in routines, processes, and artifacts.

A number of key concepts have significantly shaped the knowledge management field and the understanding of knowledge as a complex phenomenon. A good example of this is the well-known distinction between explicit and tacit knowledge 
(Polanyi, 1962; 1966). In line with this distinction, knowledge is conceived as acquired by an individual as he or she identifies, interprets, and internalizes theoretical or practical knowledge (Pries-Heje, 2004; Myers, 1996), either by hearing about a topic or by doing something. The acquired knowledge is unique to the individual because the information and experience is filtered through and "added" to the stock of knowledge that the individual already possesses. This knowledge can be used to get the work done (to a large extent by making use of tacit knowledge), and it can be articulated and codified for the benefit of others. As individual knowledge can be verbalized and (re-) used by others (Markus, 2001), different types of knowledge processes, e.g., knowledge creation, sharing, transfer, etc. as well as mechanisms that support these processes have also dominated the knowledge management discourse (see for example Nonaka and Takeuchi, 1995).

In this paper, we draw on these key concepts regarding different types of knowledge, knowledge processes, and mechanisms as our theoretical backdrop and vocabulary for understanding what knowledge is, and how it might be transferred. However, the definitions, discussions, and normative prescriptions found in the knowledge management literature are relatively abstract and philosophical in nature. Thus, even though much research about different types of knowledge and knowledge transfer mechanisms exists, there is still quite some distance to travel from the theoretical understanding and recommendations to the concrete task of establishing and executing a knowledge transfer plan for a distributed work environment.

Studies of distributed work have highlighted the impact of geographical distance and the importance of common ground, coupling of work, collaboration readiness and collaboration technology readiness, see for example (Olson and Olson, 2000). Moreover, virtual-teams research has studied the challenges concerning the creation and maintenance of trust, mutual liking and shared meaning as well as the management of conflicts in teams where members work together across time, space and culture (Bjørn and Ngwenyama, 2009; Hinds and Bailey, 2003; Hinds and Mortensen, 2005; Jarvenpaa and Leidner, 1999). Also, in the outsourcing literature the problems and influence of geographical distance, cultural differences, the onshore staff's motivation for engaging in cross-cultural interaction, and the offshore unit's lack of domain knowledge, etc. have received considerable attention (Beck et al., 2008; Carmel and Agarwal, 2002; Gregory et al., 2009). We draw on this literature to understand and support the way managers at the operational level in the company handle the knowledge transfer challenge they face.

In particular we build on the notion of common ground (Kraut et al., 2002; Olson and Olson, 2000). All communication and collaboration rest on a foundation of information, which the interaction partners have in common and which they are aware that they share (ibid.). In some situations, there is already much common ground prior to interaction because people are members of the same group or work environment, belong to the same national culture, have witnessed or experienced the same events, etc. At the same time, and partly due to the dynamic nature of everyday life, people always have to establish common ground during the particular interaction. According to the principle of 'least collaborative effort', people will try to create grounding for their interaction with as little effort as possible and, therefore, people will often prefer to interact in person rather than through written media (Kraut et al., 2002). 


\section{$3 \quad$ Research Approach}

In this work we adopt an applied approach. As such, we draw on and contribute to the existing body of knowledge with an illustration of how theoretical insights about knowledge and knowledge transfer as well as an understanding of the practical challenges of knowledge transfer in outsourcing can be applied to design a systematic approach that supports managers at the operational level in carrying out the concrete task of knowledge transfer planning and execution.

This piece of research has been conducted as part of a long-term collaboration with Danske Bank as part of a larger research project called SourceIT ${ }^{1}$. An engaged research approach has been applied to ensure production of research knowledge that is concrete and relevant for practical problem solving (Van de Ven, 2007). The research team consisted of people from both academia and industry, more specifically two academics and one practitioner from the company. The research team worked closely together to develop an empirically grounded and shared understanding of the knowledge transfer challenges in outsourcing and how they might be overcome.

Our research activities have been structured into four phases. In the first phase, the two academics spent three weeks in India in March 2009 to study the operational aspects of the outsourcing arrangement. This led to a more focused study of how to understand and support knowledge transfer, involving the practitioner from summer 2009 onwards. The practitioner was at this point in time on a 6 month posting in India and was, among other things, charged with the task of improving the company's way of conducting knowledge transfer. In the second phase, the aim was to understand the challenges of knowledge transfer in outsourcing. Over the course of a two month time period, a literature study of the knowledge management and distributed work/outsourcing literature was conducted and the results here of, delineated in overview tables and text, were jointly discussed and compared with the company's experiences. The discussions were documented in a project log, containing our emerging understandings of the knowledge transfer challenges as well as ideas for how to overcome them. In the third phase, the results from phase two (i.e. the documents and shared understanding) informed the first conceptual design of a multi-step knowledge transfer model. In the fourth phase, the knowledge transfer model gradually evolved into the conceptual design of a systematic five-step, tool supported approach to knowledge transfer. Table 1 provides an overview of the four phases and our research activities.

As Table 1 shows the information and results reported below are the product of a number of iterations between data collection at various empirical sites, analysis of empirical data, comparison of literature and practice, and presentations for the people involved in the activities studied, people with managerial positions in Danske Bank, as well as for the other companies and academic researchers in the SourceIT research project.

\footnotetext{
${ }^{1}$ The SourceIT research project lasted $3 \frac{1}{2} 2$ years (from 2008 - to mid 2011) and involved one academic institution, three large companies, and a consultancy company that specializes in dissemination of research knowledge to the broader public.
} 
Table 1. Research phases and activities

\begin{tabular}{|c|c|c|}
\hline Phases & Activities & Who and when \\
\hline 1.Building common ground & $\begin{array}{l}\text { Field study at the ODC in } \\
\text { India: } 18 \text { interviews and } \\
\text { observation } \\
\text { A short-term posting at the } \\
\text { ODC in India }\end{array}$ & $\begin{array}{l}\text { The two academics, three } \\
\text { weeks, Mar } 2009 \\
\text { The practitioner, six months, } \\
\text { Mar-Oct } 2009\end{array}$ \\
\hline $\begin{array}{l}\text { 2. Understanding the chal- } \\
\text { lenges of KT }\end{array}$ & $\begin{array}{l}\text { Literature study: Knowledge } \\
\text { management; KT in out- } \\
\text { sourcing } \\
\text { Joint conversations about the } \\
\text { results of the literature study } \\
\text { and their "fit" with and } \\
\text { manifestation in practice; } \\
\text { documented in a project log }\end{array}$ & $\begin{array}{l}\text { The research team, two } \\
\text { months, Jul-Aug } 2009\end{array}$ \\
\hline $\begin{array}{l}\text { 3. Conceptualizing a multi- } \\
\text { step model to KT }\end{array}$ & $\begin{array}{l}\text { Informed by the results from } \\
\text { phase two, a multi-step } \\
\text { model for overcoming the } \\
\text { challenges of KT was de- } \\
\text { veloped }\end{array}$ & $\begin{array}{l}\text { The research team, two } \\
\text { months, Sept-Oct } 2009\end{array}$ \\
\hline $\begin{array}{l}\text { 4. Receiving feedback and } \\
\text { refining the approach }\end{array}$ & $\begin{array}{l}\text { Workshop: Presentation of } \\
\text { KT model to the SourceIT } \\
\text { project participants } \\
\text { Workshop: Presentation of a } \\
\text { systematic five-step, tool } \\
\text { supported approach to the } \\
\text { SourceIT project partici- } \\
\text { pants } \\
\text { Presentation of the KT ap- } \\
\text { proach to another company } \\
\text { with a different outsourcing } \\
\text { arrangement to inquire about } \\
\text { the approach's broader } \\
\text { usefulness } \\
\text { Two interviews to follow-up } \\
\text { on Danske Bank's chal- } \\
\text { lenges and experiences with } \\
\text { KT }\end{array}$ & $\begin{array}{l}\text { The research team and the } \\
\text { academics and practitioners } \\
\text { in the SourceIT research } \\
\text { project, Nov } 2009 \\
\text { The research team and the } \\
\text { academics and practitioners } \\
\text { in the SourceIT research } \\
\text { project, May } 2010 \\
\text { The research team and three } \\
\text { employees involved in out- } \\
\text { sourcing, Jun } 2010\end{array}$ \\
\hline
\end{tabular}

\section{$4 \quad$ Knowledge Transfer Challenges in Case Company}

Danske Bank's outsourcing arrangement is organized as an Offshore Development Centre (ODC) in Bangalore, India. The ODC is a facility owned by an Indian vendor, but dedicated to Danske Bank. The ODC is located in four adjacent buildings that 
bear the Danish company name. Only the employees who are working for Danske Bank have access to these buildings, and they work on the same technical platform as the Danish employees. Five Danes, i.e. one manager and four Liaison Officers (LOs), are posted in India to oversee the daily operations.

The chosen strategy is such that approximately 500 Indians employed by the Indian vendor are 'hired' from the Indian company into the ODC. These Indian associates are considered a pool of resources to be allocated to IT development projects and/or system management areas, just like other IT employees in Danske Bank ${ }^{2}$. Also, many Indian resources are allocated to tasks onshore (i.e. in Denmark). A typical onshore stay lasts from two to four months. Many activities are jointly performed by Danish employees and Indian associates, regardless of whether people are co-located or collaborate virtually. In other words, a cooperative outsourcing strategy (Dibbern et al., 2004) has been implemented. In this outsourcing arrangement, knowledge transfer is very important as the establishment of common ground is crucial for efficient and smooth collaboration between the Danish employees and the Indian associates.

The knowledge transfer that takes place is essentially twofold. First, it is the obligation of the Indian vendor to hire staff with the appropriate technical skills and train them in the Danske Bank's organization, processes, and tools as well as to provide general cultural training about Denmark and the Danish work culture. In this paper, we do not focus on this initial training. Rather, we are occupied with the subsequent knowledge transfer that has to occur to provide Indian associates with the specific knowledge they need to function in the team they are assigned to. The Danish manager of the team is responsible for this knowledge transfer - which fits well with Markus's (2001) definition of 'classical' knowledge transfer to expertise-seeking novices.

With regard to the latter knowledge transfer three major types of challenges have been identified. These challenges are elaborated below.

\subsection{Knowledge Types and Needs}

All people know more than they are consciously aware of (Polanyi, 1962). In other words, people possess much tacit knowledge and therefore take many things for granted, also when transferring knowledge. Second, people have different backgrounds and levels of expertise, and thus, different knowledge (transfer) needs when assigned to similar tasks.

A simple, yet illustrative example of the challenge of tacit knowledge in the case company concerns the Danish mortgage system. Most Danish employees know that a mortgage in Denmark is a loan with the currency of up to thirty years whether it is a fixed rate mortgage or another kind of mortgage. So, in Denmark, the maximum currency is regarded somewhat as a constant. However, in India there is no such thing as a formalized maximum currency. Consequently, if the Danish maximum currency is

\footnotetext{
${ }^{2}$ An example of an IT development project that was carried out by a team consisting of both Danish and Indian employees was the re-launch of Danske Bank's web bank application, while the company's IT systems for HRM (salary payment, staffing, competence development, etc.) is an example of a system management area that is maintained (i.e. operational problems) and further enhanced (i.e. new functionality) by a team consisting of both Danes and Indians.
} 
left out of the knowledge transfer there is a risk that the Indian associates will work on the assumption that the mortgage system in Denmark is equivalent to the Indian mortgage system. There are of course an endless number of similar examples of what is so common for the Danish employees that they forget that it may not be just as common for the Indian knowledge recipients, and vice versa.

Another issue that employees of Danske Bank often face is the question of how much the Indians know prior to knowledge transfer. The Indians have different backgrounds and levels of expertise. This inhibits a clear-cut definition of what type of knowledge to transfer and how - as the needs vary from person to person.

\subsection{Physical Distance}

In line with prior research (see e.g., Olson and Olson, 2000), the experience in Danske Bank is that knowledge transfer is best done when the Indian associates are invited for an onshore stay of two to four months. Knowledge transfer happens more or less automatically when people are in close physical proximity (Kraut et al., 2002). People simply go to each other's desks and ask for help as the need arises. This fluent pattern of interaction is also exercised by onshore Indian associates. Thus, co-location of Danish employees and Indian associates means that knowledge transfer needs can be handled with low effort through "a quick chat", i.e., in a way where it does not feel like knowledge transfer.

However, there are many occasions in which an initial onshore stay is not possible for a variety of reasons. In these cases, the employees tend to use emails as the primary means of communication (for similar results see Oshri et al., 2008). From the viewpoint of the Danish employees, knowledge transfer hereby becomes a very timeconsuming affair because the experience is that a written answer takes time to produce and because an answer might trigger follow-up questions. Furthermore, the Indian associates have on many occasions expressed that they feel they are burdening the Danish employees when asking (too many) questions. At the same time, a significant number of the Danish employees are not entirely comfortable with other types of communication technologies. Moreover, the available video conferencing rooms with possibilities for shared desktops, etc. are not used unless located very close to the workspace.

\subsection{Incentives and Priorities}

Successful knowledge transfer over distance requires that the employees have an incentive to engage in this activity (Gregory et al., 2009; Lin, 2007; Markus, 2001; Olson and Olson, 2000). However, in the busy environment of Danske Bank's IT department, the Danish employees are inclined to focus their effort on what is immediately beneficial for their own work and on what gets rewarded by their local managers, namely the daily tasks and knowledge sharing with colleagues at the same location.

Moreover, at the outset of collaborating on an IT development project or in a system management area, there are clear knowledge asymmetries. Thus, in the beginning the Danish employees have knowledge that the Indian associates need. However, there are not necessarily any immediate benefits for the Danish employees in sharing their 
knowledge. In addition, it is difficult to assess the value of the time spent on answering emails and engaging in other knowledge transfer activities. Therefore, the Danish employees' motivation to do so can be quite low. Yet, in line with Heeks et al.'s (2001) findings about global software outsourcing, the experience in the company is that when the Danish employees and the Indian associates have physically met and got to know each other, email exchanges work much better. The reason is presumably that knowledge about each other as persons makes it easier for the interaction partners to know what kind of information to include in the emails (Kraut et al., 2002; Olson and Olson, 2000) and because people are more willing to help someone they have met, know, and like (Clark and Mills, 1993; Haytko, 2004).

Table 2 summarizes the experienced knowledge transfer challenges.

Table 2. Experienced challenges with knowledge transfer

\begin{tabular}{l|l|l}
\hline Type of challenge & KT challenge & $\begin{array}{l}\text { A systematic approach to KT } \\
\text { should help the manager: }\end{array}$ \\
\hline $\begin{array}{l}\text { Knowledge types and } \\
\text { needs }\end{array}$ & $\begin{array}{l}\text { Tacit knowledge. } \\
\text { Knowledge needs vary from } \\
\text { person to person. }\end{array}$ & $\begin{array}{l}\text { Identify and include (tacit) know- } \\
\text { ledge that would otherwise be } \\
\text { forgotten. } \\
\text { Identify the real needs of the } \\
\text { knowledge recipient(s). }\end{array}$ \\
\hline Physical distance & $\begin{array}{l}\text { The Danish employees consider } \\
\text { knowledge transfer time- } \\
\text { consuming due to the number of } \\
\text { questions asked via email. } \\
\text { The Indians associates feel that } \\
\text { they are burdening the Danish } \\
\text { employees with (too many) ques- } \\
\text { tions/emails. }\end{array}$ & $\begin{array}{l}\text { Identify the knowledge needs that } \\
\text { have to be met to reduce the num- } \\
\text { ber of questions from the Indian } \\
\text { to the Danish employees. } \\
\text { Identify a variety of relevant } \\
\text { knowledge transfer mechanisms. }\end{array}$ \\
\hline $\begin{array}{l}\text { Incentives and } \\
\text { Priorities }\end{array}$ & $\begin{array}{l}\text { The Danish employees focus their } \\
\text { efforts on progressing with their } \\
\text { daily work in accordance with } \\
\text { management priorities. }\end{array}$ & $\begin{array}{l}\text { Plan for and make the effort and } \\
\text { transt of knowledge transfer }\end{array}$ \\
\hline
\end{tabular}

\section{$5 \quad$ A Five-Step Approach to Knowledge Transfer}

In this section we present a systematic, tool supported approach to knowledge transfer. The approach has been developed in responds to the challenges described above. The aim of the approach is to help the Danish managers' plan and carry out knowledge transfer to Indian associates who are newcomers to a particular IT development project or system management area.

The tool is more specifically thought of as a spreadsheet solution. The Danish employees in the company are very familiar with this type of software functionality and they use it for many tasks. Moreover, several of Danske Bank's existing outsourcing assessment and decision-tools, e.g., for making tactical decisions about which IT projects and system management areas to outsource, have been implemented as spreadsheet applications (see, e.g., Jørgensen et al., 2011). 
The suggested approach consists of five steps (see Table 3). In step one a gap analysis lays the foundation for the subsequent knowledge transfer planning and execution. Thus, the Danish manager first decides what the desired or required level of knowledge is. Subsequently, the manager obtains information about the Indian associates' actual level of knowledge (via CVs and dialogue with LOs). On this basis, an assessment of the gap between the desired and the current knowledge level is made. The outcome of the analysis is an identification of the gaps that are the most severe and which therefore should be selected as the most important areas for knowledge transfer.

The tool supports the gap analysis in the following way. A number of predetermined categories (business domain, IT, process, task, and organization) and questions within each category help the manager consider what type of knowledge is particularly important for the given project/system management area. Thus, for each question, the manager sets the desired level of knowledge by using a predefined scale. Then, for each question, each Indian associate's current knowledge level is scored using the same scale. The predetermined categories, questions, and scales play an important role in ensuring that both explicit and tacit knowledge needs are addressed. The result is presented as a gap between the desired and the current level of knowledge for each question (in numbers) as well as for each category (in a diagram). The biggest deviations are highlighted so that the manager gets an overview of where the major gaps are by quickly viewing the results for each associate. Based on this analysis of the knowledge gaps, the manager actively chooses the areas for knowledge transfer. The selected focus areas are automatically moved to a new sheet that will eventually become the knowledge transfer plan.

Next identification of knowledge transfer mechanisms is included as a separate step to ensure that it is given due consideration. Thus, for each focus area a list of relevant knowledge transfer mechanisms is provided, and based on this list the manager chooses the mechanisms that s/he prefers. In this way, the tool supports the manager in realizing that there are many knowledge transfer mechanisms (such as class room training, documentation of previously undocumented IT systems and work flows, and mentoring and buddy arrangements to name but a few) and that several mechanisms might be able to address the same knowledge transfer need.

Following the selection of relevant knowledge transfer mechanisms a detailed knowledge transfer plan is made. For each selected knowledge area and transfer mechanism, a Danish employee responsible for the execution of the knowledge transfer is assigned, the Indian participants are named, and time estimates for preparation and execution, as well as room and technology requirements are outlined. In this way the tool supports the planning activity by providing the fields that ensure that the project/system manager considers the most important aspects, including some that are easily overlooked in a busy environment, such as preparation time and resource requirements. The resulting knowledge transfer plan allows for an overview of the effort that the knowledge transfer demands.

Then the knowledge transfer plan is carried out in practice, without support from the knowledge transfer tool. However, evaluation data in the form of the participants' subjective satisfaction and perceived value can be collected and stored in the spreadsheet. Moreover, the experienced challenges (see Table 2) indicate that it is important for the managers to follow-up on the effect of the knowledge transfer initiatives on two measures: productivity and the number of question-answer emails exchanges between the Indian and the Danish employees. 
Table 3. The knowledge transfer approach

\begin{tabular}{|c|c|c|}
\hline Step & Action & Tool support \\
\hline 1 & $\begin{array}{l}\text { Identify knowledge gaps } \\
\text { Identify the desired knowledge } \\
\text { level. } \\
\text { Assess the Indian associates' } \\
\text { current knowledge level. } \\
\text { Analyze the gaps between the } \\
\text { desired and the current level, } \\
\text { and select the most critical ones } \\
\text { as focus areas for knowledge } \\
\text { transfer. }\end{array}$ & $\begin{array}{l}\text { A range of predetermined catego- } \\
\text { ries and questions help the } \\
\text { manager consider what type of } \\
\text { knowledge is particularly im- } \\
\text { portant for the given } \\
\text { project/system management area. } \\
\text { For each question, each Indian } \\
\text { associate's current knowledge } \\
\text { level is scored on a scale. } \\
\text { The result is presented as a gap } \\
\text { between the desired and the current } \\
\text { level of knowledge for each ques- } \\
\text { tion as well as for each category. } \\
\text { The biggest deviations are hig- } \\
\text { hlighted. } \\
\text { The focus areas for knowledge } \\
\text { transfer are actively chosen and } \\
\text { automatically moved to a new } \\
\text { sheet that will eventually become } \\
\text { the knowledge transfer plan. }\end{array}$ \\
\hline 2 & $\begin{array}{l}\text { Identify knowledge transfer me- } \\
\text { chanisms } \\
\begin{array}{l}\text { For each of the selected focus } \\
\text { areas, knowledge transfer me- } \\
\text { chanisms are considered and } \\
\text { chosen. }\end{array} \\
\end{array}$ & $\begin{array}{l}\text { In the knowledge transfer plan, the } \\
\text { knowledge transfer mechanism(s) } \\
\text { for each focus area has to be cho- } \\
\text { sen. For inspiration, a list of } \\
\text { knowledge transfer mechanisms is } \\
\text { provided. }\end{array}$ \\
\hline 3 & $\begin{array}{l}\text { Establish the knowledge transfer } \\
\text { plan } \\
\text { A detailed knowledge transfer } \\
\text { plan is made. }\end{array}$ & $\begin{array}{l}\text { When the knowledge transfer } \\
\text { mechanisms have been chosen, } \\
\text { the other fields for knowledge } \\
\text { transfer planning are activated. } \\
\text { For each knowledge transfer } \\
\text { mechanism, it is outlined: who is } \\
\text { responsible, who participates, es- } \\
\text { timated time for preparation, esti- } \\
\text { mated time for execution, room } \\
\text { and/or technology requirements, } \\
\text { deadline etc. }\end{array}$ \\
\hline 4 & $\begin{array}{l}\text { Execute the knowledge transfer } \\
\text { plan } \\
\text { Intermediates carry out the } \\
\text { knowledge transfer. An inter- } \\
\text { mediate may be either a know- } \\
\text { ledgeable person from the Da- } \\
\text { nish organization or an expe- } \\
\text { rienced team member from the } \\
\text { ODC. }\end{array}$ & $\begin{array}{l}\text { The knowledge transfer plan is } \\
\text { carried out without support from } \\
\text { the KT tool. }\end{array}$ \\
\hline
\end{tabular}


Table 3. (continued)

\begin{tabular}{l|l|l}
\hline 5 & $\begin{array}{l}\text { Evaluate the effect of the know- } \\
\text { ledge transfer } \\
\text { Collect, store, and use data } \\
\text { about the effect of the know- } \\
\text { ledge transfer. }\end{array}$ & $\begin{array}{l}\text { No specific method for data col- } \\
\text { lection is prescribed, but data } \\
\text { about effects can be stored and } \\
\text { spreadsheet functionality used for } \\
\text { analysis. }\end{array}$ \\
\hline
\end{tabular}

\section{Discussion}

Artifacts are not just neutral objects. Instead they are constructed based on the knowledge and cultural and contextual understandings of the designers and they shape and are shaped by the situated actions of the users (Masino and Zamarian, 2003; Orlikowski, 1992, 2007). In this research we have used an understanding of extant literature as well as of the case company and its experienced challenges to suggest an artifact, namely a systematic tool supported 5-step approach to the case company's knowledge transfer. The purpose of the approach is to ensure that the planning and execution of knowledge transfer takes place in a systematic way. Moreover, through the use of a spreadsheet application, the purpose is to prompt the Danish managers to consider the distinction between explicit and tacit knowledge, to recognize that many types of relevant knowledge transfer mechanisms exist, and to conduct detailed knowledge transfer planning. In this way, the suggested approach is goal-oriented, normative, and 'mechanistic' in nature. What might the advantages and disadvantages of such an approach to knowledge transfer be?

Vilnai-Yavetz and Rafaeli (2006) propose that in order to achieve a comprehensive understanding of what artifacts are and do in organizations they should be considered according to three dimensions: instrumentality, aesthetics and symbolism. Instrumentality refers to the fact that people and organizations have tasks and goals to accomplish and an artifact can be evaluated according to whether it helps or hinders the accomplishment of these tasks and goals. Aesthetics refers to the sensory experience an artifact elicits. It has for example long been recognized that the 'look and feel' of products, such as IT systems, mobile phones, computers, etc. have a huge impact on their success (take Apple products as an example). Symbolism refers to the meanings and associations that are created in the minds of the users, and it therefore concerns the message an artifact sends.

From an instrumental perspective the suggested knowledge transfer approach facilitates goal achievement by guiding the manager through the five steps, presenting possible options in a clear and sequential way in a spreadsheet application. However, the suggested approach and use of the supporting spreadsheet application does not in itself guarantee successful knowledge transfer as there are many other factors that influence the outcome, such as, e.g., how the knowledge transfer is actually prepared and carried out by the Danish employees and the extent to which the knowledge is/can be acquired by the Indian associates. The Danish manager should therefore give due consideration to these and other practicalities in step four and five. Additionally, the company is focused on achieving process maturity and adhering to the CMMI framework for software development. The tool supported approach to knowledge 
transfer helps satisfy the three sub-goals associated with goal 2 'Provide Necessary Training' in the CMMI process area named 'Organizational Training' (Chrissis et al, 2011).

From an aesthetic perspective we have chosen to implement the suggested approach as a spreadsheet solution. In so doing, the knowledge transfer approach obtains the 'look and feel' of the way the Danish managers normally work and it caters to theirs' and the broader company culture's preference for rational decisions, numbers, and plans. Thus, a key design decision has been to 'ride with the waves' of the organizational culture. Another key design goal is to prompt, and even provoke the Danish managers into broadening their understanding of what they and their Danish employees know and how this knowledge might be transferred to the Indian associates. However, by choosing to implement the knowledge transfer approach in a way that resembles the way the managers normally work there is a risk this broader understanding might not be achieved. Especially if the spreadsheet application is used in an unreflective way to quickly produce a knowledge transfer plan. This indicates that the Danish managers should be given a theoretical introduction to what knowledge and knowledge transfer is, as well as practical information about how to use the suggested knowledge transfer approach.

From a symbolic perspective the knowledge transfer approach has been designed to fit the company culture and the way work gets done in the case company. The advantage here of, i.e. of providing tool support that facilitates rational planning, is that knowledge transfer gets legitimized as "real work". In other words, it gets recognized that it takes time to plan, prepare and conduct knowledge transfer and therefore that (top) management has to sanction and provide work hours for it. However, with this approach there is a risk that knowledge transfer will be perceived to be primarily about planning and less about execution. To counter this, step three in the suggested approach and spreadsheet application 'forces' the manager to make a detailed plan, with names, dates, resource requirements etc. However, use of the approach and application does not guarantee that the knowledge transfer plan will be carried out. It is for example not uncommon in the case company that suddenly emerging system maintenance issues, new politically implemented laws (e.g., concerning mortgages, pensions), etc. take priority over planned initiatives with longer term benefits. Thus, while the approach can help create awareness about knowledge transfer as a distinct, necessary and resource demanding activity, the awareness will only be turned into action if (top) management prioritizes it regardless of the immediate operational circumstances.

In summary the approach reduces the complexity of knowledge transfer planning by structuring the work in a way that is familiar for the Danish managers. This in turn helps legitimize the task by communicating that knowledge transfer is an activity in its own right and by making it clear what the task consists of. However, it is also clear from the above that even with a systematic and quite normative approach (that covers predetermined steps, categories, and questions that have to be adhered to) the actual use situation still offers much room for autonomy. Thus, managers can chose to forgo the fact that the spreadsheet application is intended to make them reflect, and they can instead rush through the planning activity. Moreover, even when a well-thought out and detailed knowledge transfer plan is made it still has to be executed. Here, however, the suggested knowledge transfer approach does not offer any direct support and in 
addition contextual factors and practical aspects might create barriers for the execution of the plan. We conclude that the tool supported approach is very useful for knowledge transfer planning, but additional support might be needed with regard to execution.

\section{Conclusion}

Based on our long-term engagement with an offshore outsourcing arrangement between an Indian IT vendor and a Danish financial company, we identify three main types of knowledge transfer challenges, as seen from the client side. The challenges relate to different knowledge types and needs; physical distance; and the Danes' incentives and priorities for taking time to engage in knowledge transfer. The challenges indicate that a pro-active and management initiated approach to knowledge transfer could be useful.

We suggest a systematic tool supported approach that covers five separate steps: (1) The manager identifies the knowledge gaps that are the most important to address. (2) Then, the manager selects appropriate knowledge transfer mechanisms. (3) The manager makes a detailed knowledge transfer plan. (4) The knowledge transfer plan is carried out. (5) Lastly, the effect of the knowledge transfer is evaluated.

Workshop tests indicate that the suggested approach is able to help the Danish manager conduct detailed knowledge transfer planning that overcomes the identified knowledge transfer challenges. However, due to the 'messy' nature of daily life at the operational level, the execution of the knowledge transfer plan can still be subject to a number of contextual and practical barriers and managerial reprioritizations. In other words, the existence of a plan does not guarantee its successful execution, and as the company starts to work more systematically with knowledge transfer new challenges related to practical implementation of the knowledge transfer plan will arise and have to be overcome.

On a meta-level a key finding of this research is that it takes substantial work, i.e. literature study, empirical research, design considerations, and trial-and-error implementation, to 'translate' existing theoretical insights about different types of knowledge and knowledge transfer mechanisms to the practical realm. As such our main contribution is to demonstrate (1) how theoretical concepts can be used to inform the analysis of a particular company's outsourcing setup and experienced knowledge transfer challenges and (2) how the achieved understanding can serve as the foundation for designing a practical approach to knowledge transfer planning and execution that fits with and borrows legitimacy from the company culture.

We believe that similar work, and effort, is needed in all companies that wish to implement a knowledge transfer approach that overcomes the challenges associated with their specific outsourcing setup. However, we also believe that the three identified knowledge transfer challenges that pertain to this case as well as the five steps in the suggested knowledge transfer approach are a relevant inspiration and starting point for other companies. 


\section{References}

Beck, R., Gregory, R., Prifling, M.: Cultural intelligence and project management interplay IT offshore outsourcing projects. In: Proceedings of the 29th International Conference on Information Systems, Paris, France, December 14-17 (2008)

Bjørn, P., Ngwenyama, O.: Virtual team collaboration: Building shared meaning, resolving breakdowns and creating translucence. Information Systems Journal 19, 227-253 (2009)

Carmel, E., Agarwal, R.S.: Tactical approaches for alleviating distance in global software development. IEEE Software, 22-29 (March/April 2001)

Carmel, E., Agarwal, R.S.: The maturation of offshore sourcing of information technology work. MIS Quarterly Executive 1(2), 65-77 (2002)

Clark, M., Mills, J.: The difference between communal and exchange relationships: What it is and is not. Personality and Social Psychology Bulletin 19, 684 (1993)

Dibbern, J., Goles, T., Hirschheim, R., Jayatilaka, B.: Information systems outsourcing: A survey and analysis of the literature. Database for Advances in Information Systems 35(4), 6-102 (2004)

Chrissis, M., Konrad, M., Shrum, S.: CMMI for Development (2011)

Haytko, D.: Firm-to-firm and interpersonal relationships: Perspectives from advertising agency account managers. Journal of the Academy of Marketing Science 32, 312-328 (2004)

Heeks, R., Krishna, S., Nicholson, B., Sahay, S.: Synching or Sinking: Global software outsourcing relationships. IEEE Software, 54-60 (March/Apil 2001)

Hinds, P.J., Bailey, D.E.: Out of Sight, Out of Sync: Understanding Conflict in Distributed Teams. Organization Science 14(6), 615-632 (2003)

Hinds, P.J., Mortensen, M.: Understanding conflict in geographically distributed teams: the moderating effects of shared identify, shared context, and spontaneous communication. Organization Science 16(3), 290-307 (2005)

Gregory, R., Prifling, M., Beck, R.: The role of cultural intelligence for the emergence of negotiated culture in IT offshore outsourcing projects. Information Technology \& People 22(3), 223-241 (2009)

Jarvenpaa, S.L., Leidner, D.E.: Communication and trust in global virtual teams. Organization Science 10(6), 791-815 (1999)

Jørgensen, C., Korsaa, M., Olesen, A.B.: Decision support tool for tactical sourcing. In: Hertzum, M., Jørgensen, C. (eds.) Balancing Sourcing and Innovation in Information Systems Development, Tapir Academic Publishers, Trondheim (2011)

Kotlarsky, J., Oshri, I.: Social ties, knowledge sharing and successful collaboration in globally distributed system development projects. European Journal of Information Systems 14, 37 48 (2005)

Kraut, R.E., Fussel, S.R., Brennan, S.E., Siegel, J.: Understanding effects of proximity on collaboration: Implications for technologies to support remote collaborative work. In: Hinds, P.J., Kiesler, S. (eds.) Distributed Work, pp. 137-162. MIT Press, Cambridge (2002)

Lin, H.-F.: Effects of extrinsic and intrinsic motivation on employee knowledge sharing intentions. Journal of Information Science 33(2), 135-149 (2007)

Markus, M.L.: Toward a theory of knowledge reuse: Types of knowledge reuse situations and factors in reuse success. Journal of Management Information Systems 18(1), 57-93 (2001)

Masino, G., Zamarian, M.: Information technology artefacts as structuring devices in organizations: Design, appropriation and use issues. Interacting with Computers 15, 693-707 (2003)

Myers, P.S.: Knowledge management and organizational design: An introduction. In: Myers, P.S. (ed.) Knowledge Management and Organizational Design, pp. 1-6. ButterworthHeinemann, Boston (1996) 
Nonaka, I.: The knowledge-creating company. Harvard Business Review, 96-104 (1991)

Nonaka, I.: A dynamic theory of organizational knowledge creation. Organization Science 5(1), 14-37 (1994)

Nonaka, I., Takeuchi: The Knowledge Creating Company. How Japanese Companies Create the Dynamics of Innovation. Oxford University Press (1995)

Olson, G., Olson, J.S.: Distance Matters. Human Computer Interaction 15, 139-178 (2000)

Orlikowski, W.J.: The duality of technology: Rethinking the concept of technology in organizations. Organization Science 3(3), 398-427 (1992)

Orlikowski, W.J.: Sociomaterial practices: Exploring technology at work. Organization Studies 28(9), 1435-1448 (2007)

Oshri, I., Kotlarsky, J., Willcocks, L.: Socialization in a global context: Lessons from dispersed teams. In: Panteli, N., Chiasson, M. (eds.) Exploring Virtuality within and Beyond Organizations: Social, Global and Local Dimensions, pp. 21-54. Palgrave Macmillan, N.Y. (2008)

Oshri, I., van Fenema, P., Kotlarsky, J.: Knowledge transfer in globally distributed teams: The role of transactive memory. Information Systems Journal 18, 593-616 (2008)

Polanyi, M.: Personal Knowledge: Toward a Post-critical Philosophy. Harper Torchbooks, New York (1962)

Polanyi, M.: The Tacit Dimension. Anchor Day Books, New York (1966)

Pries-Heje, J.: Managing Knowledge in IT Projects. The IFCAI Journal of Knowledge Management 4, 49-62 (2004)

Rollag, K., Parise, S., Cross, R.: Getting new hires up to speed quickly. MIT Sloan Management Review 46(2), 35-41 (2005)

Van de Ven, A.H.: Engaged Schorlarship, A guide for Organizational and Social Research. Oxford University Press, NY (2007)

Vilnai-Yavetz, I., Rafaeli, A.: Managing artifacts to avoid artifact myopia. In: Rafaeli, A., Pratt, M.G. (eds.) Artifacts and Organizations, Beyond Mere Symbolism. Lawrence Erlbaum Associates, Mahwah (2006)

Yin, R.K.: Case Study Research: Design and Methods. Sage Publications, Newbury Park (1994) 